\title{
Prevalence and Resolution of Resistant Left Atrial Appendage Thrombus in Non-Valvular Atrial Fibrillation Patients Submitted to Percutaneous Interventions
}

Fabricio Vassallo ${ }^{1,2,3}$, Lucas Luis Meigre ${ }^{1}$, Eduardo Serpa ${ }^{1,2,3}$, Betina Resck ${ }^{1,2}$, Ariane Leal ${ }^{4}$, Carlos Volponi ${ }^{1,2,3}$, Christiano Cunha ${ }^{1,2,3}$, Hermes Carloni ${ }^{1,2,3}$, Aloyr Simoes Jr. ${ }^{1,2,3}$, Karla Meira ${ }^{1,2}$, Flavia Pezzin ${ }^{1,2}$, Dalton Amaral ${ }^{1,2}$, Dalbian Gasparini ${ }^{1,2}$.

${ }^{1}$ Instituto de Cardiologia do Espírito Santo.

${ }^{2}$ Santa Rita de Cassia Hospital.

${ }^{3}$ Santa Casa de Misericórdia Hospital Vitoria.

${ }^{4}$ Multiscan Diagnostic Medicine.

*Corresponding Author: Fabricio Sarmento Vassallo, Electrophysiologist - Medical Coordinator of Electrophysiology in Instituto de Cardiologia do Espírito Santo and Santa Casa de Misericórdia Hospital

Received Date: March 26, 2021; Accepted Date: April 08, 2021; Published Date: April 15, 2021

Citation: Fabricio Vassallo., Lucas L. Meigre., Eduardo Serpa., Betina Resck., Ariane Leal., et al., (2021) Prevalence and Resolution of Resistant Left Atrial Appendage Thrombus in Non-Valvular Atrial Fibrillation Patients Submitted to Percutaneous Interventions. J. Clinical Cardiology and Cardiovascular Interventions, 4(8); Doi:10.31579/2641-0419/161

Copyright: (c) 2021 Fabricio Sarmento Vassallo, This is an open-access article distributed under the terms of the Creative Commons Attribution License, which permits unrestricted use, distribution, and reproduction in any medium, provided the original author and source are credited.

\begin{abstract}
:
Introduction: Left atrial appendage (LAA) thrombus in atrial tachyarrhythmias is one of the principal causes of stroke. Prevalence and strategies to thrombus resolution has recently been described in the era of the direct oral anticoagulants (DOAC). The aim of the study was to determine the prevalence and strategies to resolve previous LAA thrombus during regular oral antithrombotic therapy in preparation to perform atrial fibrillation (AF) ablation and/or LAA closure.

Methods: Between January 2011 and December 2020 we prospectively followed 23 patients (5.39\%) that showed LAA thrombus formation. Persistent AF occurred in 13 (56.52\%), median age 72.39 years, 15 (65.22\%) females, median CHA2DS2VASC of 4.13, HASBLED of 2.28, 17 (73.91\%) with hypertension, $(52.17 \%)$ with coronary disease, 9 $(39.13 \%)$ had priors' thromboembolic events, 7 (30.43\%) with heart failure and Diabetes. Diagnosis was by transesophageal echocardiogram (TEE) in $20(86.96 \%)$ and the rest by computed angiotomography. Rivaroxaban was used in $11(47.83 \%)$, Dabigatran in $6(26.09 \%), 5(21.74 \%)$ with therapeutic range Warfarin and $1(4.34 \%)$ with Apixaban. Main strategy of treatment was to change mechanism of action of antithrombotic medication in association to an antiplatelet drug, Clopidogrel $75 \mathrm{mg}$ a day, and perform a TEE at 90 days after.

Results: Complete resolution of the LAA thrombus was achieved in 18 (78.26\%) patients in first medical therapeutic change. Of the remaining a second approach with medical therapy adjustment with off-label dose prescription associated with Clopidogrel showed complete resolution in $3(13.04 \%)$ totalizing a success rate of $91.30 \%$ for all patients ( $p$ value of 0.001 for treatment success). The failure of the antithrombotic plus antiplatelet therapy occurred in $2(8.7 \%)$ patients, one with LAA sludge and other with a huge thrombus in all LAA and part of left atrium.
\end{abstract}

Conclusion: Modification of the mechanism of action of direct oral anticoagulants in association with Clopidogrel demonstrates to be successful in a large number of patients with previous resistant left atrial thrombus with and secure since the low adverse event rates.

Key words: left atrial appendage; left atrial appendage thrombus; atrial fibrillation; anticoagulation; transesophageal echocardiography; direct acting oral anticoagulants.

\section{Introduction:}

Atrial fibrillation (AF) predisposes to left atrial (LA) stasis and subsequent formation of left atrial appendage (LAA) thrombus, which can lead to cardioembolic stroke or systemic embolization1.
Direct current cardioversion or catheter ablation are usually performed in AF patients within a strategy rhythm control option, for symptoms relief and to rapidly restore sinus rhythm $[1,2,3]$. However, both cardioversion and catheter ablation, by inducing atrial stunning and endothelial damage, 
are associated with a not negligible risk of peri-procedural stroke or systemic embolism [4-7], being this risk maximal in the presence of left atrial appendage (LAA) thrombus8,9. For this reason, pre-procedural transesophageal echocardiography (TEE) is strongly recommended to screen for the presence of LAA thrombus $[3,10,11]$. Calkins et al. in current guidelines suggest that in patients with an AF duration of more than 48 hours or of unknown duration, three weeks of anticoagulation at a therapeutic level are needed before cardioversion or catheter ablation. However, in most cases, pre-procedural TEE and LA Computed Angiotomography is performed in all AF patients, despite an adequate anticoagulation and a not negligible incidence of LAT has been documented even among patients who have been therapeutically anticoagulated [12].

Although there is substantial evidence regarding efficacy of direct current oral anticoagulants (DOACs) for thromboembolic prophylaxis in patients with AF, efficacy of treatment in patients with pre-existing left atrial appendage thrombus is limited to a few case reports $[13,14]$ and one registry of modest size in which rivaroxaban and dabigatran was utilized $[15,16]$.

We aimed to determine the efficacy of the change in the mechanism of action of direct oral anticoagulants (DOACs) in association to antiplatelet therapy with clopidogrel in the resolution of resistant LAA thrombus utilizing transesophageal echocardiographic (TEE) and clinical outcomes.

\section{Materials and Methods:}

In the present study, 427 consecutive patients between January 2011 and December 2020 that were prepared for catheter ablation and/or LAA closure. The inclusion criteria was 23 patients $(5.39 \%)$ that showed LAA thrombus formation resistant to regular use of adequate doses of anticoagulant therapy (Figure 1).

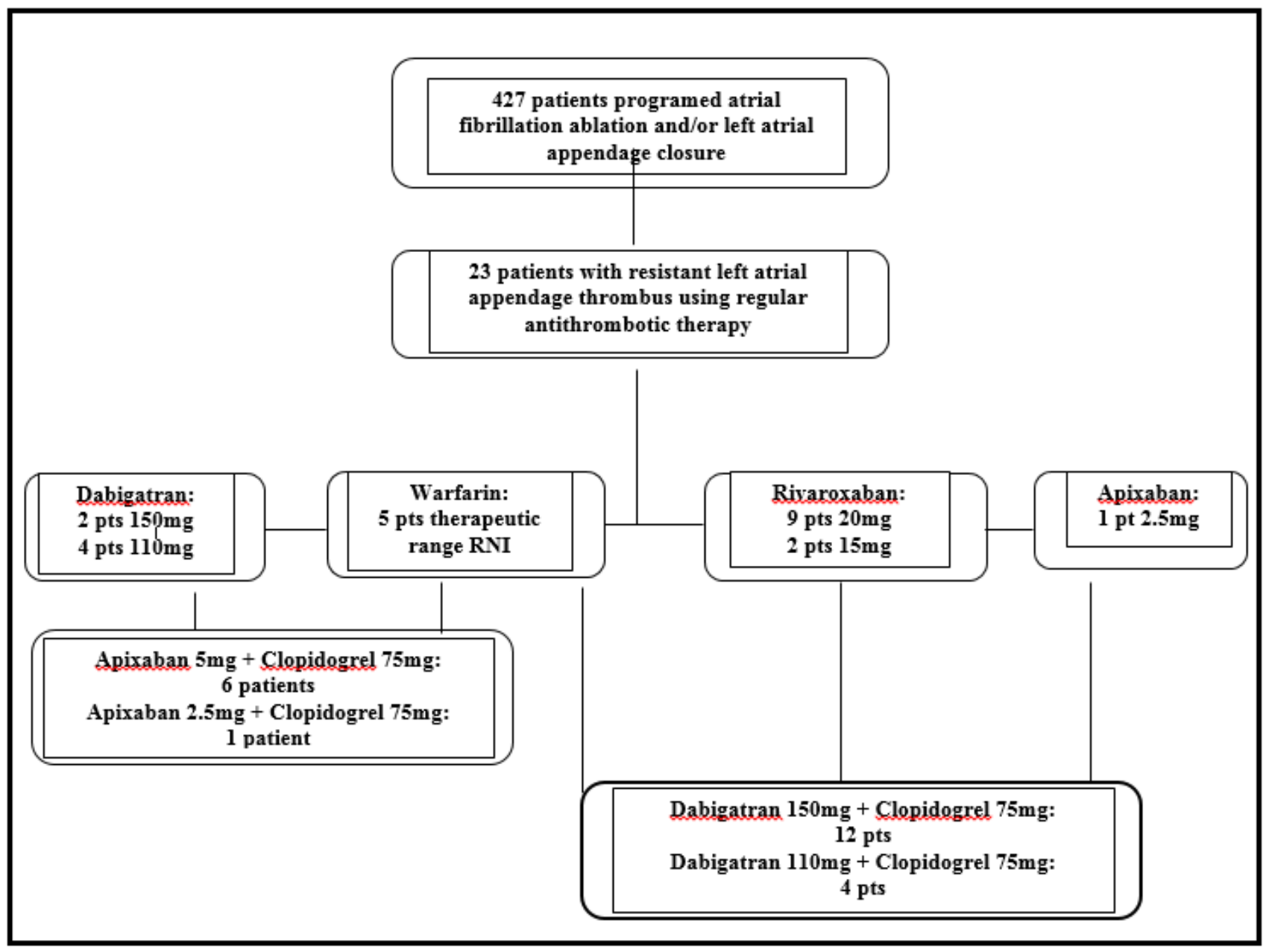

Figure 1: Schematic study flow-chart. Pts= patients.

The diagnosis of LAA was made by transesophageal echocardiogram (TEE) in $20(86.96 \%)$ patients and in $3(13.04 \%)$ by computed angiotomography [17] (Figures 2,3 and 4). The examination of these patients was made by experienced physicians and were confirmed by a second physician thereafter.

\begin{tabular}{|c|c|}
\hline Previous thromboembolic events & $\mathbf{1 2}(\mathbf{5 2 . 1 7 \%})$ \\
\hline Heart failure & $9(39.13 \%)$ \\
\hline Diabetes Mellitus & $7(30.43 \%)$ \\
\hline Mean left atrial volume & $7(30.43 \%)$ \\
\hline
\end{tabular}

Table 1: Clinical features of the patients with resistant left atrial appendage thrombus. 
The diagnosis of LAA was made by transesophageal echocardiogram (TEE) in $20(86.96 \%)$ patients and in $3(13.04 \%)$ by computed angiotomography ${ }^{17}$ (Figures $\mathbf{2 , 3}$ and 4 ). The examination of these patients was made by experienced physicians and were confirmed by a second physician thereafter.

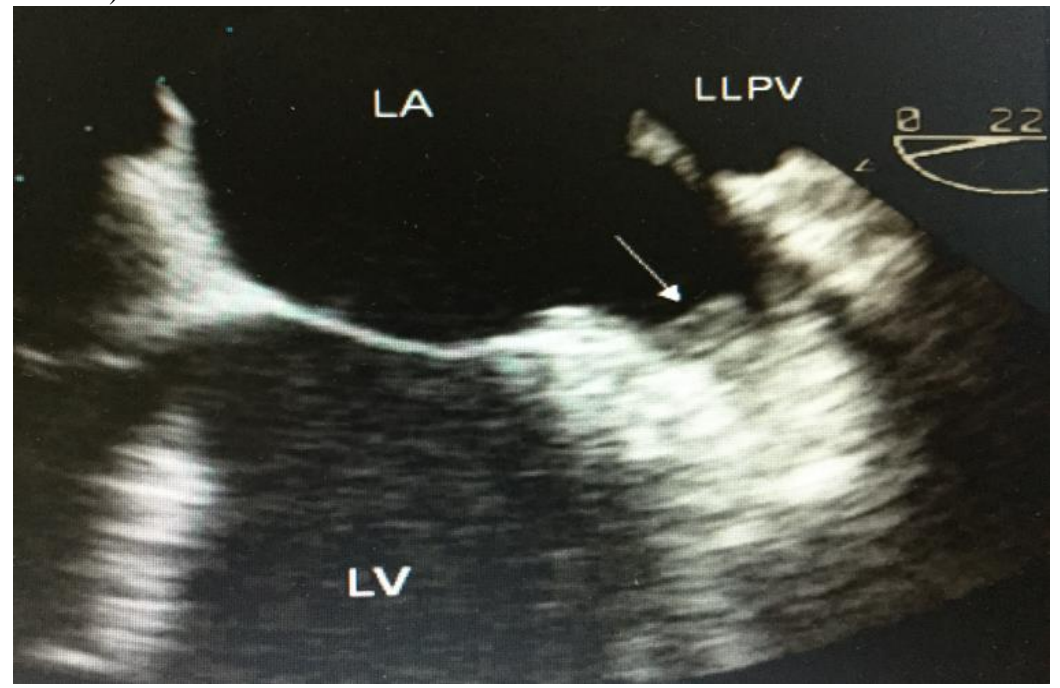

Figure 2: Transesophageal echocardiogram detecting left atrial appendage thrombus (thrombus formation showed by the arrow).

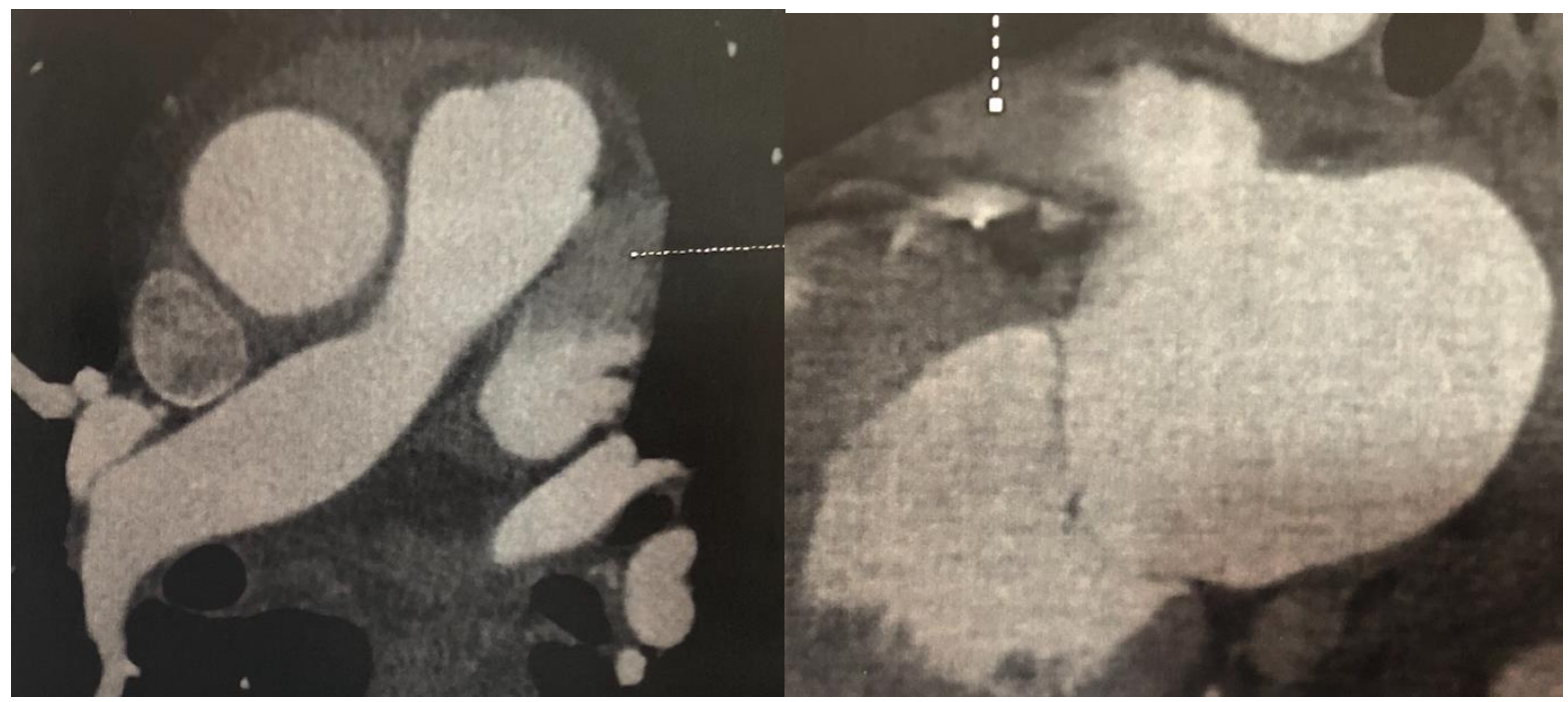

Figures 3 and 4: Left atrium computed angiotomography detecting left atrial appendage thrombus (thrombus formation showed by the arrows)

Rivaroxaban was used in $11(47.83 \%)$, followed by Dabigatran $6(26.1 \%)$, therapeutic range warfarin presented in $5(21.73 \%)$ cases and only $1(4.34 \%)$ patient using Apixaban (Table 2).

\begin{tabular}{|c|c|c|c|c|c|}
\hline PATIENT \# & $\begin{array}{c}\text { AGE } \\
\text { (YEARS) }\end{array}$ & $\mathrm{CHA}_{2} \mathrm{DS}_{2} \mathrm{VASC}$ & $\begin{array}{c}\text { TYPE OF } \\
\text { AFib }\end{array}$ & $\begin{array}{l}\text { Creatinine } \\
\text { Clearance }\end{array}$ & $\begin{array}{c}\text { ACO } \\
\text { THERAPY }\end{array}$ \\
\hline$\# 1$ & 71 & 4 & LONG-PERSISTENT & 40.09 & WARFARIN \\
\hline$\# 2$ & 68 & 3 & PAROXYSMAL & 66.56 & WARFARIN \\
\hline$\# 3$ & 71 & 4 & LONG-PERSISTENT & 58.26 & WARFARIN \\
\hline$\# 4$ & 62 & 2 & PAROXYSMAL & 84.36 & DABIGATRAN 150MG \\
\hline$\# 5$ & 77 & 4 & PERSISTENT & 45.20 & DABIGATRAN 110MG \\
\hline \# 6 & 73 & 5 & PAROXYSMAL & 39.63 & DABIGATRAN 110MG \\
\hline$\# 7$ & 68 & 4 & PAROXYSMAL & 74.98 & RIVAROXABAN 20MG \\
\hline$\# 8$ & 66 & 3 & PERSISTENT & 67.23 & RIVAROXABAN 20MG \\
\hline
\end{tabular}




\begin{tabular}{|c|c|c|c|c|c|}
\hline \# 9 & 69 & 3 & PERSISTENT & 77.67 & RIVAROXABAN 20MG \\
\hline \# 10 & 71 & 4 & PAROXYSMAL & 80.28 & RIVAROXABAN 20MG \\
\hline \# 11 & 73 & 4 & PAROXYSMAL & 55.30 & RIVAROXABAN 20MG \\
\hline \# 12 & 78 & 5 & LONG-PERSISTENT & 32.40 & APIXABAN $2.5 \mathrm{MG}$ \\
\hline \# 13 & 69 & 4 & LONG-PERSISTENT & 60.26 & RIVAROXABAN 20MG \\
\hline \# 14 & 82 & 6 & PERSISTENT & 31.89 & RIVAROXABAN 15MG \\
\hline \# 15 & 65 & 4 & PAROXYSMAL & 75.46 & WARFARIN \\
\hline \# 16 & 71 & 5 & PAROXYSMAL & 83.67 & RIVAROXABAN 20MG \\
\hline \# 17 & 75 & 4 & LONG-PERSISTENT & 27.89 & WARFARIN \\
\hline \# 18 & 74 & 7 & PAROXYSMAL & 45.06 & DABIGATRAN 110MG \\
\hline \# 19 & 83 & 4 & LONG-PERSISTENT & 48.02 & DABIGATRAN 110MG \\
\hline \# 20 & 81 & 3 & LONG-PERSISTENT & 59.45 & DABIGATRAN 150MG \\
\hline \# 21 & 71 & 3 & PERSISTENT & 59.90 & RIVAROXABAN 20MG \\
\hline \# 22 & 69 & 4 & PAROXYSMAL & 61.28 & RIVAROXABAN 20MG \\
\hline \# 23 & 78 & 6 & PERSISTENT & 36.67 & RIVAROXABAN 15MG \\
\hline
\end{tabular}

Table 2: Clinical characteristics and medical therapy of the patients.

Since the aim of the study was the complete resolution of a resistant LAA thrombus our strategy was to change the mechanism of action of the antithrombotic medication and associate empirically an antiplatelet, chosen one was clopidogrel $75 \mathrm{mg}$, and repeat in 90 days thereafter a new TEE, that was performed and revised by the same operators. After the diagnosis of the LAA thrombus Dabigatran $150 \mathrm{mg}$ b.i.d. was prescribed in association to Clopidogrel $75 \mathrm{mg}$ for $12(52.17 \%)$ patients, Dabigatran $110 \mathrm{mg}$ b.i.d. plus Clopidogrel $75 \mathrm{mg}$ for $4(17.39 \%)$ patients, Apixaban $5 \mathrm{mg}$ b.i.d. in association to Clopidogrel $75 \mathrm{mg}$ in $6(26.09 \%)$ and Apixaban $2.5 \mathrm{mg}$ b.i.d. plus Clopidogrel $75 \mathrm{mg}$ for $1(4.35 \%)$ patient (Table 3).

\begin{tabular}{|c|c|c|c|c|}
\hline Patient \# & $\begin{array}{l}\text { TYPE OF } \\
\text { AFib }\end{array}$ & $\begin{array}{c}\text { FAILED ACO } \\
\text { THERAPY }\end{array}$ & $\begin{array}{l}\text { Creatinine } \\
\text { Clearance }\end{array}$ & $\begin{array}{c}\text { NEW ACO THERAPY + } \\
\text { CLOPIDOGREL 75MG }\end{array}$ \\
\hline$\# 1$ & LONG-PERSISTENT & WARFARIN & 40.09 & DABIGATRAN 110MG \\
\hline$\# 2$ & PAROXYSMAL & WARFARIN & 66.56 & DABIGATRAN 150MG \\
\hline$\# \mathbf{3}$ & LONG-PERSISTENT & WARFARIN & 58.26 & DABIGATRAN 150MG \\
\hline$\# 4$ & PAROXYSMAL & DABIGATRAN 150MG & 84.36 & APIXABAN 5MG \\
\hline$\# \mathbf{5}$ & PERSISTENT & DABIGATRAN 110MG & 45.20 & APIXABAN 5MG \\
\hline$\# 6$ & PAROXYSMAL & DABIGATRAN 110MG & 46.63 & APIXABAN 5MG \\
\hline$\# 7$ & PAROXYSMAL & RIVAROXABAN 20MG & 74.98 & DABIGATRAN 150MG \\
\hline$\# 8$ & PERSISTENT & RIVAROXABAN 20MG & 67.23 & DABIGATRAN 150MG \\
\hline$\# 9$ & PERSISTENT & RIVAROXABAN 20MG & 77.67 & DABIGATRAN 150MG \\
\hline \# 10 & PAROXYSMAL & RIVAROXABAN 20MG & 80.28 & DABIGATRAN 150MG \\
\hline \# 11 & PAROXYSMAL & RIVAROXABAN 20MG & 55.30 & DABIGATRAN 150MG \\
\hline \# 12 & LONG-PERSISTENT & APIXABAN $2.5 \mathrm{MG}$ & 32.40 & DABIGATRAN 110MG \\
\hline \# 13 & LONG-PERSISTENT & RIVAROXABAN 20MG & 60.26 & DABIGATRAN 150MG \\
\hline \# 14 & PERSISTENT & RIVAROXABAN 15MG & 31.89 & DABIGATRAN 110MG \\
\hline \# 15 & PAROXYSMAL & WARFARIN & 75.46 & DABIGATRAN 150MG \\
\hline \# 16 & PAROXYSMAL & RIVAROXABAN 20MG & 83.67 & DABIGATRAN 150MG \\
\hline \# 17 & LONG-PERSISTENT & WARFARIN & 27.89 & APIXABAN 2.5MG \\
\hline \# 18 & PAROXYSMAL & DABIGATRAN 110MG & 45.06 & APIXABAN 5MG \\
\hline \# 19 & LONG-PERSISTENT & DABIGATRAN 110MG & 48.02 & APIXABAN 5MG \\
\hline \# 20 & LONG-PERSISTENT & DABIGATRAN 150MG & 59.45 & APIXABAN 5MG \\
\hline \# 21 & PERSISTENT & RIVAROXABAN 20MG & 59.90 & DABIGATRAN 150MG \\
\hline \# 22 & PAROXYSMAL & RIVAROXABAN 20MG & 61.28 & DABIGATRAN 150MG \\
\hline \# 23 & PERSISTENT & RIVAROXABAN 15MG & 36.67 & DABIGATRAN 110MG \\
\hline
\end{tabular}

Table 3: Clinical characteristics of the patients and prior failure therapy and new anticoagulants. 


\section{Statistical analysis:}

All tests were performed using BioStat statistical software (AnalystSoft Walnut, CA, USA). Continuous variables were expressed as meanstandard deviation. A result was considered significant if $P$ value of $<.05$.

\section{Results:}

Between the 23 patients, persistent AF was present in $13(56.52 \%)$ patients, median age 66.08 (62 to 83 ) years, $15(65.22 \%)$ of females, median $\mathrm{CHA}_{2} \mathrm{DS}_{2} \mathrm{VASC}$ of 3.77 (2 to 7), HASBLED of 2.28 (1 to 5), 17 $(73.91 \%)$ with hypertension, $(52.17 \%)$ with coronary disease, $9(39.13 \%)$ had previous thromboembolic events, $7(30.43 \%)$ with heart failure and 7 $(30.43 \%)$ Diabetes Mellitus (Table 1).
After a 90-days new antithrombotic plus antiplatelet regimen we achieved a complete resolution of the LAA thrombus in a total of $18(78.26 \%)$ patients. Of the remaining $5(21.74 \%)$ patients a second attempt with medical therapy adjustment to a higher dose off-label prescription of the same DOAC with maintenance of Clopidogrel showed complete resolution in $3(60 \%)$ of these 5 patients, determining a total success rate of $91.30 \%$ ( $p$ value of 0.001 ). All of these 5 patients, 4 (80\%) were using Dabigatran 110mg b.i.d. and 1 (20\%) using Apixaban b.i.d. 2.5mg, both adjusted dosages because of the renal impairment. The failure of the antithrombotic plus antiplatelet therapy occurred in two patients, one with the use of Apixaban who showed a partial resolution of the LAA thrombus but remained with a sludge (Figure 5) inside the LAA and other using Dabigatran which remained with a huge thrombus in all LAA and part of left atrium (Figures 6 and 7).

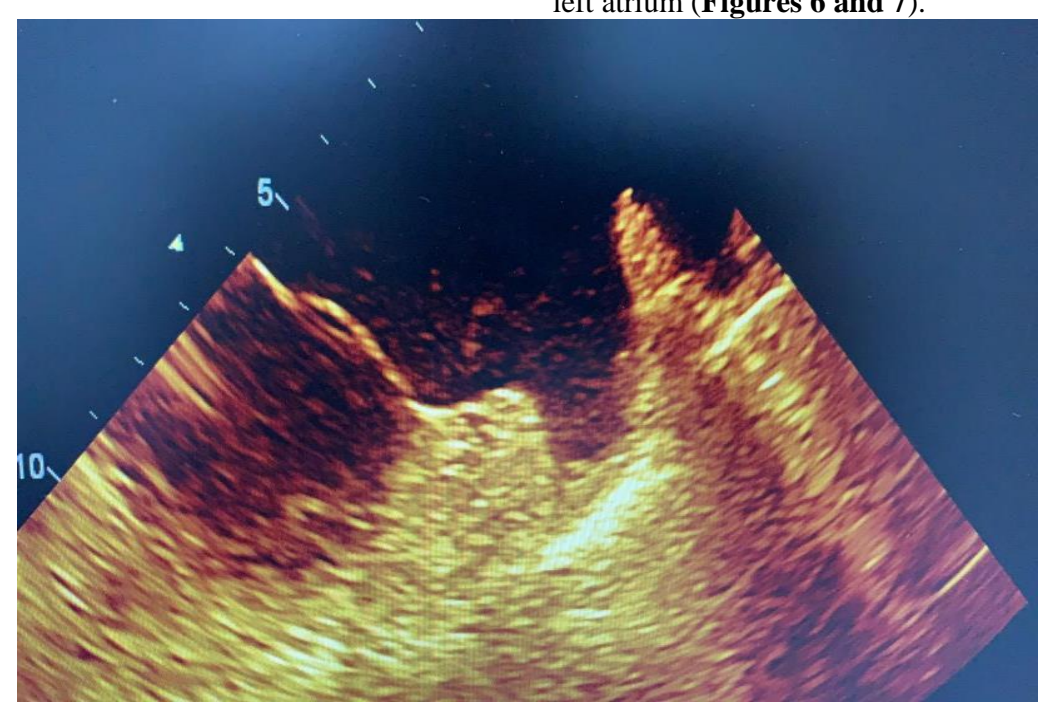

Figure 5: Transesophageal echocardiogram showing a remaining sludge inside the left atrial appendage (showed by the arrow).

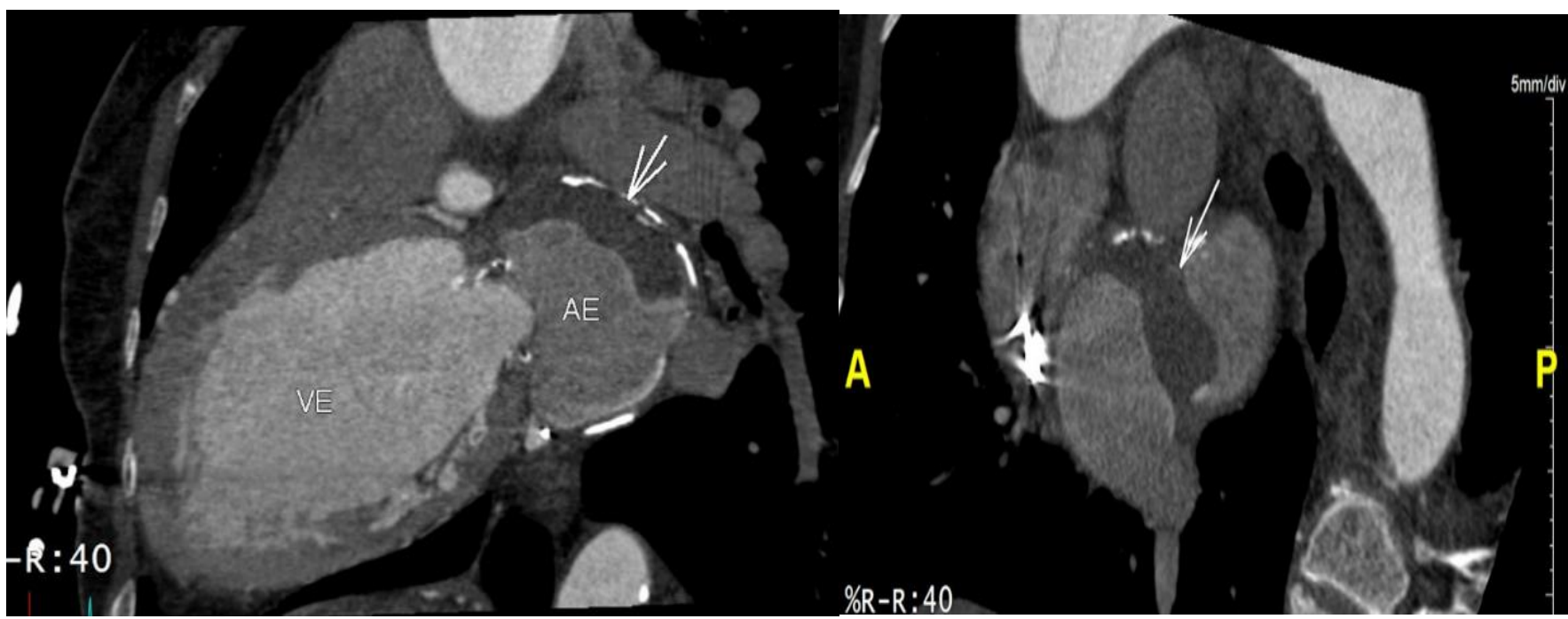

Figures 6 and 7: Computed angiotomography showing a remaining a huge thrombus inside the left atrium (showed by the arrows). 


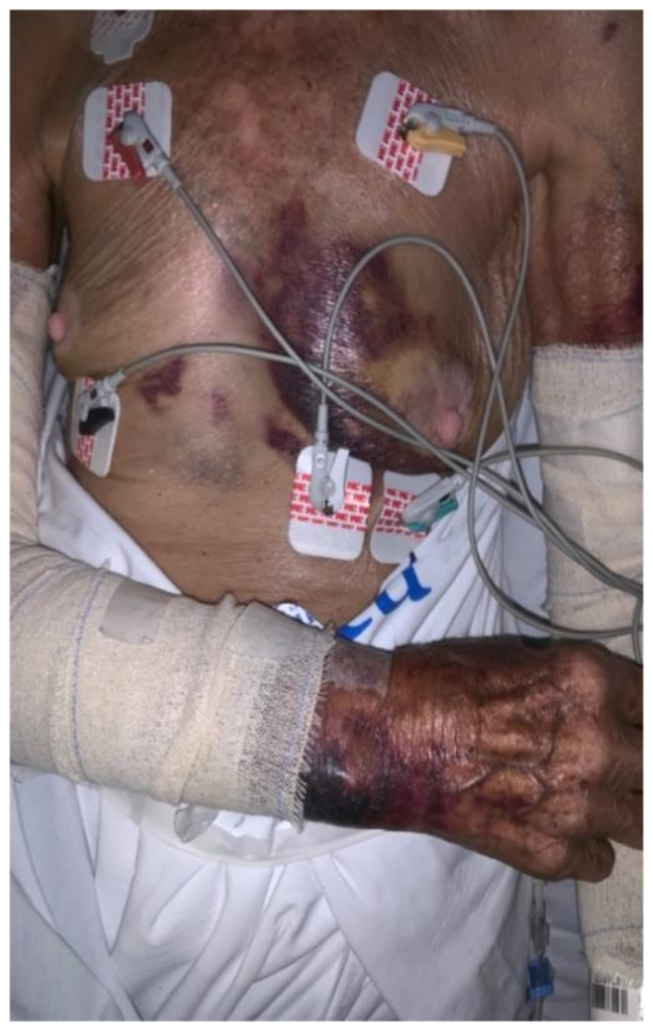

Figure 8: Extensive subcutaneous hemorrhage in a patient with an off-label dosage prescription of a direct oral anticoagulant.

In these patients submitted to an off-label prescription we observed minor bleeding in 2 such as gingival or nasal spontaneous bleeding and major bleeding such as gastrointestinal and large subcutaneous hemorrhages that not required hospital admission in 3 patients.

The clinical characteristics of the patients are as followed; $\geq 71$ years, all with persistent and long-persistent atrial fibrillation, $\mathrm{CHA}_{2} \mathrm{DS}_{2} \mathrm{VASC} \geq$ 4; left atrial volume of $\geq 47 \mathrm{ml} / \mathrm{m}^{2}$, the creatinine clearance was $\leq$ $40 \mathrm{ml} / \mathrm{min}$, rest heart rate observed commonly was $\geq 85 \mathrm{bpm}, 4(80 \%)$ patients had heart failure with left ventricular ejection fraction of $\leq 45 \%$ and $4(80 \%)$ were female gender.

\section{Discussion:}

Atrial fibrillation is commonly associated with formation of left atrial appendage (LAA) thrombus which can lead to thromboembolic events. Traditionally, warfarin has been the primary anticoagulant used for patients with AF [18]. In 2009, the RE-LY trial in patients with AF showed that dabigatran reduced stroke risk in patients with atrial fibrillation without increasing the risk of major bleeding as compared to warfarin [19]. In 2011, the ROCKET-AF trial demonstrated that rivaroxaban was non-inferior to warfarin in preventing stroke or another systemic thromboembolism in a similar patient population [20]. Also, in 2011, the ARISTOTLE trial showed that apixaban was associated with a lower incidence of stroke and/or thromboembolism, and a decrease in the incidence of bleeding, as compared to traditional anticoagulation therapy with warfarin in patients with atrial fibrillation [21,22]. Although these studies demonstrated efficacy in thromboembolic prophylaxis in patients with AF [23], there is limited data regarding use of these agents to treat patients with pre-existing LAA thrombus [24-26].

Complete LA thrombus resolution is mandatory prior to performing procedures within the LA, such as catheter ablation for AF and LA appendage occlusion [27]. Reasonable confidence in LA thrombus resolution rates would provide guidance as to the optimal time to reschedule procedures.

DOACs have become common in clinical practice for thromboembolic prophylaxis in nonvalvular, and recently in patients with $\mathrm{AF}$ and biological valves [28], AF following several landmarks randomized controlled trials that demonstrated noninferiority to warfarin [29]. Nevertheless, there is uncertainty regarding the application of these results for the management of LA thrombus. To the best of our knowledge, there have been only five publications on NOACs to date where all or the majority of subjects with $\mathrm{AF}$ or flutter were oral anticoagulant (OAC) naïve at the time of initial diagnosis of LA thrombus [26,30-33].

Hao et al [30] reported intracardiac thrombus resolution by TEE in 19 of $22(89.5 \%)$ subjects after three months of treatment with dabigatran 150 mg b.i.d. This prospective study, performed at Qilu Hospital of Shandong University, was notable for having a warfarin comparison group with resolution in 17 of $22(77.3 \%)$ subjects. However, prior OAC use was present in three subjects in the dabigatran group and eight subjects in the warfarin arm.

Lip et al [26] conducted the Xarelto-ThRombus Accelerated resolution (X-TRA) multicenter prospective study throughout seven countries.20 Rivaroxaban dosage was $20 \mathrm{mg}$ b.i.d., or $15 \mathrm{mg}$ b.i.d. in the case of renal impairment. The LA thrombus resolution rate was only $41.5 \%$ (95\% CI, $28.1 \%-55.9 \%$ ) in 60 subjects after mean treatment duration of 46 days. Of these subjects, $23.3 \%$ had prior OAC use. Results from the rivaroxaban treatment group were compared to 156 patients from a multicenter retrospective registry who were treated with five different VKA agents. Two important limitations included different time periods of patient recruitment and marked differences in baseline characteristics between treatment groups. 
Xing et al administered dabigatran $150 \mathrm{mg}$ q.d. to subjects with nonrheumatic $\mathrm{AF}$ and LA thrombi confined to the appendage who presented to General Hospital of Shenyang Military Command of PLA [31]. TEE was performed after 3 months of DOAC treatment. In 58 subjects, complete LA appendage thrombus resolution was observed in only $15(25.9 \%)$. Lack of prior long-term OAC use at the time of initial LA thrombus diagnosis was not explicitly reported.

Fleddermann et al reported a retrospective cohort study from St. Luke's Mid America Heart Institute in 16 patients with AF who were treated with NOACs for LA appendage thrombus [32]. None of the patients received $\mathrm{OAC}$ agents prior to the index medical encounter. Complete resolution was demonstrated in 9 of $9(100 \%)$ patients who received apixaban, 4 of $4(100 \%)$ patients who received dabigatran, and 2 of $3(67 \%)$ patients who received rivaroxaban. The median time between initial and follow-up TEEs was 66 days (range, 33 to 2000 days). TEEs were reviewed by a cardiologist blinded to the $\mathrm{OAC}$ agents received.

Ke et al conducted a randomized controlled trial of rivaroxaban $20 \mathrm{mg}$ q.d. versus warfarin for LA thrombus detected on TEE in 80 subjects who were scheduled for catheter ablation for nonvalvular AF at The First Affiliated Hospital of Guangxi Medical University [33]. All subjects were free of OAC for one month prior to LA thrombus diagnosis and $80 \%$ were confined to the LA appendage. Repeat TEEs were performed at 6 weeks and 12 weeks. At 6 weeks, complete LA thrombus resolution was observed in six $(15 \%)$ subjects in the rivaroxaban group and $0(0 \%)$ subjects in the warfarin group $(\mathrm{P}=.01)$. At 12 weeks, complete resolution was observed in $32(80 \%)$ subjects in the rivaroxaban group and $28(70 \%)$ subjects in the warfarin group $(\mathrm{P}=.30)$.

Ultimately, multicenter randomized controlled trials to compare individual DOACs to warfarin or other DOACs should be performed.

The REsolution of Left atrial-Appendage Thrombus-Effects of Dabigatran [34] in patients with Atrial Fibrillation (RE-LATED AF) study was designed to randomize 110 subjects with nonvalvular AF and LA appendage thrombus diagnosed on TEE to dabigatran versus the VKA phenprocoumon ${ }^{34}$. Follow-up TEE will be performed after at least 3 weeks and up to a maximum of 6 weeks after the initial TEE. Patients with LA appendage thrombus that formed while receiving $>3$ months of a VKA will be excluded from enrollment.

From our knowledge this is the first report of a strategy in patients with previous and resistant LAA thrombus for the complete resolution of the issue. The empirical use of an antiplatelet drug such as Clopidogrel associated to a DOAC and in some cases the prescription of an off-label dosage of these medications can explain the high success rate of the manuscript.

\section{Limitations:}

A series of limitations must be addressed in the present study.

First this is an observational, small sample sized study with retrospective analysis. Second it was a non-randomized and with no control group. Third the lack of the LA appendage emptying speed and thrombus size weight in the fact that these two features may impact in thrombus resolution.

\section{Conclusion:}

In the present study when we performed the modification of vitamin-K antagonists to direct oral anticoagulants and change the mechanism of action of these drugs in association to an antiplatelet thienopyridine derivate demonstrates to be a successful strategy in a large number of patients with previous resistant left atrial thrombus and secure since the low adverse event rates.

\section{Acknowledgements:}

For their dedication and effort in data collection and patience, we appreciate the dedication of Christiane Amaral and Vanessa Rodrigues from the administration staff and Edevaldo da Silva, Rafael Zeni and Anderson Barcelos from the biomedical team.

Financial support: This study had no source of financial support.

Conflicts of interest: all authors declare no conflicts of interest.

\section{References:}

1. Zoni-Berisso M, et al. Frequency, patient characteristics, treatment strategies, and resource usage of atrial fibrillation (from the Italian Survey of Atrial Fibrillation Management (ISAF) study). Am J Cardiol 2013; 111: 705-711.

2. Wann LS, et al. 2011 ACCF/AHA/HRS focused update on the management of patients with atrial fibrillation (update on dabigatran): a report of the American College of Cardiology Foundation/American Heart Association Task Force on practice guidelines. J Am Coll Cardiol 2011; 57: 1330-1337.

3. Calkins H, et al. 2012 HRS/EHRA/ECAS expert consensus statement on catheter and surgical ablation of atrial fibrillation: recommendations for patient selection, procedural techniques, patient management and follow-up, definitions, endpoints, and research trial design: a report of the Heart Rhythm Society (HRS) Task Force on Catheter and Surgical Ablation of Atrial Fibrillation. Developed in partnership with the European Heart Rhythm Association (EHRA), a registered branch of the European Society of Cardiology (ESC) and the European Cardiac Arrhythmia Society (ECAS); and in collaboration with the American College of Cardiology (ACC), American Heart Association (AHA), the Asia Pacific Heart Rhythm Society (APHRS), and the Society of Thoracic Surgeons (STS). Endorsed by the governing bodies of the American College of Cardiology Foundation, the American Heart Association, the European Cardiac Arrhythmia Society, the European Heart Rhythm Association, the Society of Thoracic Surgeons, the Asia Pacific Heart Rhythm Society, and the Heart Rhythm Society. Heart Rhythm. 2012; 9: 632-696.e21.

4. Scherr D, et al. Incidence and predictors of periprocedural cerebrovascular accident in patients undergoing catheter ablation of atrial fibrillation. J Cardiovasc Electrophysiol 2009; 20: 13571363.

5. Lown B, et al. "Cardioversion" of atrial fibrillation: a report on the treatment of 65 episodes in 50 patients. N Engl J Med 1963; 269: 325-331.

6. Jensen JB, Humphries JO, Kouwenhoven WB, et al. Electroshock for atrial flutter and atrial fibrillation: follow-up studies on 50 patients. J Am Med Assoc 1965; 194: 1181-1184.

7. Vazquez SR, et al. Peri-procedural anticoagulation in patients undergoing ablation for atrial fibrillation. Thromb Res 2010; 126 : e69-77.

8. Fuster V, et al. ACC/AHA/ESC 2006 Guidelines for the Management of Patients with Atrial Fibrillation: a report of the American College of Cardiology/American Heart Association Task Force on Practice Guidelines and the European Society of Cardiology Committee for Practice Guidelines (Writing Committee to Revise the 2001 Guidelines for the Management of Patients with Atrial Fibrillation): developed in collaboration with the European Heart Rhythm Association and the Heart Rhythm Society. Circulation 2006; 114: e257-354.

9. Chimowitz MI, et al. Left atrial spontaneous echo contrast is highly associated with previous stroke in patients with atrial fibrillation or mitral stenosis. Stroke 1993; 24: 1015-1019. 
10. Camm AJ, et al. 2012 focused update of the ESC Guidelines for the management of atrial fibrillation: an update of the 2010 ESC Guidelines for the management of atrial fibrillation. Developed with the special contribution of the European Heart Rhythm Association. Eur Heart J 2012; 33: 2719-2747.

11. January CT, et al. 2014 AHA/ACC/HRS guideline for the management of patients with atrial fibrillation: a report of the American College of Cardiology/ American Heart Association Task Force on Practice Guidelines and the Heart Rhythm Society. J Am Coll Cardiol 2014; 64: e1-76.

12. Atrial Fibrillation Investigators. Risk factors for stroke and efficacy of antithrombotic therapy in atrial fibrillation. Analysis of pooled data from five randomized controlled trials. Arch Intern Med 1994; 154: 1449-1457.

13. Kawakami T, Kobayakawa H, Ohno H, Tanaka N, Ishihara H. Resolution of left atrial appendage thrombus with apixaban. Thromb J 2013; 11:26-29.

14. Li Y, Lin J, Peng C. Resolution of massive left atrial appendage thrombi with rivaroxaban before balloon mitral commissurotomy in severe mitral stenosis: A case report and literature review. Medicine 2016;95: e5577.

15. Lip GY, Hammerstingl C, Marin F, Cappato R, Meng IL, Kirsch B, van Eickels M, Cohen A; X-TRA study and CLOT-AF registry investigators. Left atrial thrombus resolution in atrial fibrillation or flutter: Results of a prospective study with rivaroxaban (XTRA) and a retrospective observational registry providing baseline data (CLOT-AF). Am Heart J 2016; 178:126-134.

16. Mitamura $H$, Nagai $T$, Watanabe A, Takatsuki $S$ and Okumura $K$. Left atrial thrombus formation and resolution during dabigatran therapy: A Japanese Heart Rhythm Society report. Journal of Arrhythmia 31(2015)226-231.

17. Pathan F, Hecht H, Narula J and Marwick TH. Roles of Transesophageal Echocardiography and Cardiac Computed Tomography for Evaluation of Left Atrial Thrombus and Associated Pathology. A Review and Critical Analysis. J Am Coll Cardiol Img 2018; 11:616-627.

18. European Atrial Fibrillation Trial Study G. Optimal oral anticoagulant therapy in patients with nonrheumatic atrial fibrillation and recent cerebral ischemia. N Engl J Med 1995; 333:5-10.

19. Connolly SJ, Ezekowitz MD, Yusuf S, Eikelboom J, Oldgren J, Parekh A, Pogue J, Reilly PA, Themeles E, Varrone J, Wang S, Alings M, Xavier D, Zhu J, Diaz R, Lewis BS, Darius H, Diener HC, Joyner CD, Wallentin L; RE-LY Steering Committee and Investigators. Dabigatran versus warfarin in patients with atrial fibrillation. N Engl J Med 2009; 361:1139-1151.

20. Patel MR, Mahaffey KW, Garg J, Pan G, Singer DE, Hacke W, Breithardt G, Halperin JL, Hankey GJ, Piccini JP, Becker RC, Nessel CC, Paolini JF, Berkowitz SD, Fox KA, Califf RM; ROCKET AF Investigators. Rivaroxaban versus warfarin in nonvalvular atrial fibrillation. N Engl J Med 2011; 365:883-891.

21. Granger CB, Alexander JH, McMurray JJ, Lopes RD, Hylek EM, Hanna M, Al-Khalidi HR, Ansell J, Atar D, Avezum A, Bahit MC, Diaz R, Easton JD, Ezekowitz JA, Flaker G, Garcia D, Geraldes M, Gersh BJ, Golitsyn S, Goto S, Hermosillo AG, Hohnloser SH,
Horowitz J, Mohan P, Jansky P, Lewis BS, Lopez-Sendon JL, Pais P, Parkhomenko A, Verheugt FW, Zhu J, Wallentin L; ARISTOTLE Committees and Investigators. Apixaban versus warfarin in patients wi th atrial fibrillation. N Engl J Med 2011; 365:981-992.

22. Eikelboom J, Merli G. Bleeding with direct oral anticoagulants vs warfarin: clinical experience. Am J Emerg Med 2016; 34:3-8.

23. Dobesh PP, Fanikos J. Direct oral anticoagulants for the prevention of stroke in patients with nonvalvular atrial fibrillation: understanding differences and similarities. Drugs 2015; 75:16271644.

24. Kawakami T, Kobayakawa H, Ohno H, Tanaka N, Ishihara H. Resolution of left atrial appendage thrombus with apixaban. Thromb J 2013; 11:26-29.

25. Li Y, Lin J, Peng C. Resolution of massive left atrial appendage thrombi with rivaroxaban before balloon mitral commissurotomy in severe mitral stenosis: A case report and literature review. Medicine 2016;95: e5577.

26. Lip GY, Hammerstingl C, Marin F, Cappato R, Meng IL, Kirsch $\mathrm{B}$, van Eickels M, Cohen A; X-TRA study and CLOT-AF registry investigators. Left atrial thrombus resolution in atrial fibrillation or flutter: Results of a prospective study with rivaroxaban (XTRA) and a retrospective observational registry providing baseline data (CLOT-AF). Am Heart J 2016; 178:126-134.

27. Zhan Y, Joza J, Al Rawahi M, et al. Assessment and management of the left atrial appendage thrombus in patients with nonvalvular atrial fibrillation. Can J Cardiol. 2018; 34:252-261.

28. Guimarães HP, Lopes RD, de Barros e Silva PG, et al., on behalf of the RIVER Trial Investigators. Rivaroxaban in Patients with Atrial Fibrillation and a Bioprosthetic Mitral Valve. N Engl J Med 2020; 383:2117-2126.

29. Kovacs RJ, Flaker GC, Saxonhouse SJ, et al. Practical management of anticoagulation in patients with atrial fibrillation. J Am Coll Cardiol. 2015; 65:1340-1360.

30. Hao L, Zhong J, ZhangW, et al. Uninterrupted dabigatran versus warfarin in the treatment of intracardiac thrombus in patients with nonvalvular atrial fibrillation. Int J Cardiol. 2015; 190:63-66.

31. Xing XF, Liu NN, Han YL, Zhou WW, Liang M, Wang ZL. Anticoagulation efficacy of dabigatran etexilate for left atrial appendage thrombus in patients with atrial fibrillation by transthoracic and transesophageal echocardiography. Medicine. 2018;97: e11117.

32. Fleddermann A, Eckert R, Muskala P, Hayes C, Magalski A, Main ML. Efficacy of direct acting oral anticoagulant drugs in treatment of left atrial appendage thrombus in patients with atrial fibrillation. Am J Cardiol. 2019; 123:57-62.

33. Ke HH, He Y, Lv XW, Zhang EH, Wei Z, Li JY. Efficacy and safety of rivaroxaban on the resolution of left atrial/left atrial appendage thrombus in nonvalvular atrial fibrillation patients. J Thromb Thrombolysis. 2019; 48:270-276.

34. Ferner M, Wachtlin D, Konrad T, et al. Rationale and design of the RE-LATED AF-AFNET 7 trial: Resolution of left atrialappendage thrombus-effects of dabigatran in patients with atrial fibrillation. Clin Res Cardiol. 2016; 105:29-36. 
This work is licensed under Creative Commons Attribution 4.0 License

To Submit Your Article Click Here: Submit Manuscript

DOI: $10.31579 / 2641-0419 / 161$
Ready to submit your research? Choose Auctores and benefit from:

* fast, convenient online submission

* rigorous peer review by experienced research in your field

* rapid publication on acceptance

* authors retain copyrights

* unique DOI for all articles

* immediate, unrestricted online access

At Auctores, research is always in progress.

Learn more www.auctoresonline.org/journals/clinical-cardiology-andcardiovascular-interventions 